Viso - Cadernos de estética aplicada Revista eletrônica de estética

ISSN 1981-4062

$N^{\circ} 15,2014$

http://www.revistaviso.com.br/

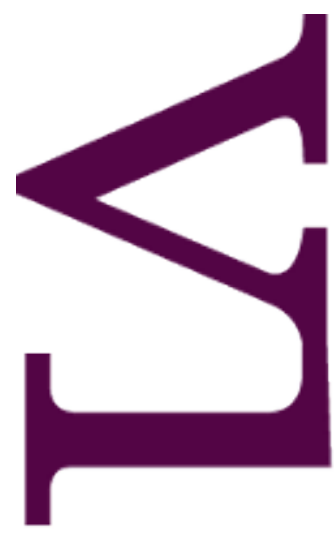

ก

0

\title{
O sujeito está na arte
}

Tania Rivera 


\section{RESUMO}

\section{O sujeito está na arte}

"Wo Es war, soll Ich werden" (Ali onde isso estava, eu devo advir). Uma das frases mais célebres da história da psicanálise se inicia com uma referência espacial, contida na partícula "wo" (onde). Partindo dessa constatação, o artigo mostra como as obras de Cildo Meireles (Estudo para espaço) e Laura Lima (Grande), ao subverterem nossa construção imaginária do espaço, provocam um descentramento do eu e uma subversão do sujeito análogos ao que ocorre em uma análise.

Palavras-chave: Lacan - espaço - sujeito - arte contemporânea

\section{ABSTRACT}

\section{The Subject is in Art}

"Wo Es war, soll Ich werden" (Where this was, shall I become). One of the most famous lines in the history of psychoanalysis begins with a spatial reference, contained in the word "wo" (where). From this starting point, this paper shows how works by Cildo Meireles (Estudo para espaço) and Laura Lima (Grande) subvert our imaginary construction of space, thus causing a dislocation of the ' $l$ ' and a subversion of the subject which is analogous to a psychoanalysis session.

Keywords: Lacan - space - subject - contemporary art 


\section{RIVERA, T. "O sujeito está na arte". In: Viso: Cadernos de estética aplicada, v. VIII, n. 15 (jan-dez/2014), pp. 236-247.}

DOI: $10.22409 / 1981-4062 / v 15 i / 188$

Aprovado: 14.10.2014. Publicado: 31.01.2015.

(C) 2014 Tania Rivera. Esse documento é distribuído nos termos da licença Creative Commons Atribuição-NãoComercial 4.0 Internacional (CC-BY-NC), que permite, exceto para fins comerciais, copiar e redistribuir o material em qualquer formato ou meio, bem como remixá-lo, transformá-lo ou criar a partir dele, desde que seja dado o devido crédito e indicada a licença sob a qual ele foi originalmente publicado.

Licença: http://creativecommons.org/licenses/by-nc/4.0/deed.pt_BR

Accepted: 14.10.2014. Published: 31.01.2015.

(C) 2014 Tania Rivera. This document is distributed under the terms of a Creative Commons Attribution-NonCommercial 4.0 International license (CC-BY-NC) which allows, except for commercial purposes, to copy and redistribute the material in any medium or format and to remix, transform, and build upon the material, provided the original work is properly cited and states its license.

License: http://creativecommons.org/licenses/by-nc/4.0/ 
O sujeito não tem uma relação com a Cultura: ele está na Cultura. De saída, devemos considerar que ele jamais se encontra fora dela, e talvez só nela possa estar. Nunca somos, mas apenas podemos estar, em desconforto, mal-estar, na Cultura - campo de que cada um deve se apropriar, mas que permanecerá sempre do Outro. A expressão freudiana "mal-estar na cultura" presta-se a essa leitura literal, em português, e mesmo que o Unbehagen alemão não a respalde, confirma-se aqui que cada língua, em uma tradução, não apenas experimenta seus limites como pode agregar o saber que the é próprio.

A arte e a literatura formam um amplo campo que, na Cultura, é aquele justamente designado para que surja o sujeito, fora dele mesmo - já que seu íntimo está fora, é êxtimo, no neologismo de Lacan. ${ }^{1}$

Apresentarei neste ensaio alguns trabalhos de arte contemporânea que me ajudarão a pensar tal presença precária do sujeito na Cultura. Não estarão acompanhados por imagens, não por eu considerá-las acessórias ou desnecessárias, mas porque optei por apresentar em ato a ideia de que a arte não se esgota na imagem. A produção artística busca, muitas vezes, realizar uma reflexão sobre o imaginário que é capaz de revirá-lo e levá-lo a dar notícias do Real - o registro concebido por Jacques Lacan como aquele que está mais próximo do inconsciente.

Talvez o maior pensador do imaginário, Lacan é também seu maior crítico. Nisso ele não estava inteiramente sozinho, mas seguia uma tendência que Stéphane Mallarmé já enunciava em 1885 ao afirmar que "o moderno desdenha imaginar". ${ }^{2} \mathrm{E}$ que as vanguardas do início do século XX exploraram de modos diversos, em afirmativas como a de Tristan Tzara, no Manifesto Dada 1918: "tudo que se olha é falso". ${ }^{3}$ Em 1899, Freud já denunciava o fato de nossas lembranças mais vívidas poderem ser fantasias que encobrem vivências que permanecem ocultas - e talvez. ${ }^{4}$ Ele assim assinalava o trauma, ponto central da concepção do inconsciente que, como ele o caracterizava alguns anos antes, é a Outra Cena - o avesso, supõe-se, da cena do consciente, do eu. Mas também daquela que começa a reinar, quase absoluta, na Cultura do fim de século que vê surgir o cinema como cena quase perfeita, após a fotografia, décadas mais cedo, ter realizado a façanha de mimetizar quase perfeitamente a realidade. ${ }^{5}$

Afinado tanto com Freud quanto com a arte de seu tempo, Lacan concebe o registro do Simbólico como aquele no qual a linguagem domina justamente ao se destacar do campo do significado, reafirmando sua materialidade poética. Ele ecoava, assim, além dos avanços recentes da linguística e da antropologia, a radical exploração da linguagem realizada pela vanguarda literária de seu tempo, de que se aproximou principalmente através dos surrealistas e, mais tarde, de James Joyce. Antes deles, em 1913, a materialidade significante da linguagem já fora afirmada em sua potência poética pelo poeta russo Kruchenykh com seus poemas sem significação, visando criar uma nova língua, selvagem e universal, assim como, poucos anos mais tarde, pelo suíço Hugo Ball 
com seus provocativos poemas feitos de meros fonemas, e não de palavras.

Já a distinção lacaniana entre os registros do Real e do Imaginário retoma o contraste entre a Outra Cena freudiana e a cena ilusória que ela pressupõe como seu oposto. A enérgica purgação do imaginário empreendida por Lacan no início de seu ensino tinha o importante objetivo de livrar o campo da psicanálise de uma imaginarização excessiva, que obscurecia o lugar da linguagem e corria o risco de restituir ao eu um lugar de destaque. $O$ ensino do psicanalista francês sublinha que, se o eu se constitui, numa linha de ficção, a partir da fixidez ilusória do reflexo do corpo no espelho, o sujeito do inconsciente deste se destaca em nome da verdade do trauma.

A própria realidade, uma vez denunciada sua substância ficcional, é portanto problematizada em prol de um obscuro Real que não cessa de não se inscrever. Algo de fundamental resiste à significação e não se deixa tomar inteiramente nas malhas da linguagem. A partir de Freud e Lacan, é hoje corrente a ideia de que é com isso (o das Es freudiano) que tem a ver a arte.

Mas não basta apontar para este campo esquivo como para uma terra prometida, ainda que definida negativamente. Parece-me imperativo pensar hoje em caracterizações e formulações afirmativas a respeito do Real. Em geral, ele é definido por formulações deficitárias: como campo que permanece fora do sentido, por exemplo, ou como aquilo que não se inscreve (ou melhor: não cessa de não se inscrever, e devemos convir que a insistência não deixa de ser algo positivamente definido). É nesse ponto que o diálogo com o campo da arte mostra-se não como uma mera aplicação ou extensão da Psicanálise para fora do campo que Ihe seria de direito, aquele da clínica psicanalítica, mas sim como recurso metodológico fundamental para a reflexão metapsicológica. Pois a arte fornece indicações a respeito dos modos pelos quais o Real insiste em não se inscrever, e de como eles aparecem na Cultura.

Talvez a ideia freudiana do "mal-estar na Cultura" indique justamente que é na Cultura que isso não cessa de não se inscrever.

\section{Um espaço para o sujeito}

No Salão da Bússola, em 1969, Cildo Meireles apresentou um trabalho, intitulado Estudo para espaço, que consiste em três proposições apresentadas como textos datilografados em papel A4. Segue o texto de uma delas:

Estudo para área: por meios acústicos (sons). Escolha um local (cidade ou campo), pare e concentre-se atentamente nos sons que você percebe, desde os próximos até os longínquos. 
$\mathrm{Na}$ contracorrente do diagnóstico um pouco apressado segundo o qual a arte contemporânea visaria prioritariamente o choque, esta delicada proposta mostra, com vigor, que se trata de incitar o sujeito a experimentar sua posição no mundo. Ao convidálo a delimitar a área ao redor de si pelos sons - e não pela visualidade que costuma presidir, ao menos nos videntes, a organização imaginária do espaço - essa proposição incita a um descentramento, uma flexibilização do lugar fixo que a cena da fantasia concede ao Eu.

Não deve surpreender que o espaço seja levado em consideração na reflexão sobre o sujeito do inconsciente, pois Freud e Lacan o colocaram implicitamente em primeiro plano - o primeiro com suas tópicas psíquicas, o segundo com seu recurso à topologia. Estou sugerindo, levando isso um pouco mais longe, que o espaço seja tomado como oposto da imagem. Lacan já nos dava pistas disso no início de seu texto seminal sobre o estádio do espelho, referindo-se ao ato de reconhecimento da imagem do próprio corpo:

Esse ato, com efeito, longe de se esgotar, como no caso do macaco, no controle - uma vez adquirido - da inanidade da imagem, logo repercute, na criança, uma série de gestos em que ela experimenta ludicamente a relação dos movimentos assumidos pela imagem com seu meio refletido $[\ldots]^{6}$

Ao gesticular, brincando com a correspondência entre o corpo e a imagem, a criança percebe a inanidade da imagem e a distância que a separa do corpo. Essa distância, e o que está além dela, configura o espaço no qual ela se situa e pode mover-se. Longe de conferir apenas a ilusão de uma imagem unificada em uma posição fixa, o reconhecimento de si no espelho implica, assim, uma cisão entre tal imagem e o que está fora do espelho: o corpo fora da imagem, as sensações cenestésicas, os sons e tudo aquilo, enfim, que nela não se inscreve, mas fica de fora, no espaço real.

A inscrição da imagem corporal na cena do mundo permite a montagem de uma firme orientação visual (no caso dos videntes), que comanda os outros sentidos em prol do estabelecimento de um lugar para o Eu. Tal situação do Eu sustenta, implicitamente, a construção narrativa ficcional da fantasia.

Mas se o Eu toma como base a fixidez da imagem, o sujeito dela se descola, movente, em um espaço que as coordenadas simbólicas da geometria (que podemos dizer correspondentes àquelas da fantasia) não conseguem ordenar. "Espaço não existe apenas para o olho", escreve o artista russo El Lissitzky em 1923, "ele não é um quadro; se quer viver nele".7 O questionamento da primazia da visão pode assim ir de par com a crítica da representação e a busca de um surgimento do sujeito para além das amarras da cena fantasística, em um outro espaço. Trata-se de um espaço vivo e subversivo aquele mesmo que Lacan, assim como vários artistas de seu tempo, vai buscar na topologia.

"Alguma coisa no espaço", sentencia Merleau-Ponty em 1960, "escapa a nossas 
tentativas de sobrevoo". ${ }^{8}$ A cena do Eu se baseia na ilusão de tal sobrevoo. Mas algo no espaço aponta para uma inquietante Outra Cena.

A noção freudiana do Estranho (das Unheimliche) não deixa de apontar um certo desregramento espacial correlativo ao questionamento da situação do Eu. A estranheza de Ernst Jensen, no texto que dá a Freud o élan para elaborar sua própria noção, aponta para uma desorientação no espaço, ao ligá-la a uma "falta de orientação":

Com a palavra estranho (unheimlich), a língua alemã parece ter produzido uma feliz formação. Sem dúvida, esta palavra parece expressar que alguém a quem acontece algo estranho não está bem "em casa" ou "familiarizado" (heimisch) com uma dada situação, que essa coisa é ou ao menos parece ser estranha (fremd). Em suma, a palavra sugere que uma falta de orientação (Mangel an Orientierung) está ligada à impressão de estranheza de uma coisa ou. ${ }^{9}$

Mesmo que Jentsch traga em seguida para o primeiro plano a "incerteza intelectual" que Freud nele destaca, permanece forte em sua concepção a conotação espacial do Estranho como aquilo que põe o homem para fora de sua própria casa, desorientando-o. O psicanalista não deixa de reportar este fator, um pouco rapidamente, como parte da contribuição de seu predecessor: "Quanto mais orientada uma pessoa estiver em seu ambiente (Umwelt), menos facilmente ela receberá das coisas ou eventos que aí se produzem a impressão de estranheza". ${ }^{10}$ Nessa trilha, o Estranho de Freud vem indicar uma desorientação do eu correlativa a uma oscilação na cena do mundo. De repente, eu é deslocado de seu lugar, ele não é mais senhor em sua casa. Se estaria em um espelho? Todo o tema do duplo inscreve-se nessa dúvida. Ou se estaria em um quadro? Haveria algo para além da cena? O espelho e a organização fantasística que o sustenta se problematizam e, como ponto essencial da experiência estética, deixa-se entrever uma Outra Cena.

\section{O escuro}

A exposição Grande (na Casa França-Brasil, Rio de Janeiro, em dezembro de 2010/fevereiro de 2011), de Laura Lima, "flerta com a obscuridade da criação", segundo declaração oral da própria artista. E também se coloca em relação com o peso da arquitetura desse belo prédio neoclássico, acentuando e dialogando com o que nela seria historicamente opressor, segundo Laura.

Vou comentar sucintamente dois dos trabalhos nela apresentados. Na sala principal, a instalação Caos é uma profusão de elementos, uma construção ao mesmo tempo precária e delicada. Estantes que parecem prestes a cair, mesas abarrotadas de objetos, "coisas suspensas no tempo, flutuando, caindo", como descreve a artista. Trata-se de uma espécie de ateliê ou laboratório de criação. Há um ator que Laura identifica com um mágico, e ele está ali trabalhando, mostrando a "cozinha", digamos, da criação, e assim 
desmitificando-a, pois se trata de um mágico "de mangas curtas", literalmente: seus truques estão todos à mostra. A cena da arte não é mais aquela da ilusão, ela não se sustenta mais por uma cena subtraída, mas coincide com ela, mostrando seu forro, seu avesso.

Essa operação de reviramento do imaginário se radicaliza em Escolha, intervenção realizada em uma das salas laterais deste espaço expositivo de modo a impedir qualquer entrada de luz. Por espessas cortinas, entra-se sozinho no local, sem se ter ideia do que ali se encontra. Mesmo quem conhece a sala perde subitamente qualquer referência, em tal escuridão. Nessa extrema desorganização espacial, há pessoas que rapidamente deixam a peça, confirmando que "solidão, silêncio e escuridão" são fatores, como diz Freud no final um tanto abupto de "O estranho", sobre os quais só se pode dizer que são ligados à angústia infantil "que na maioria dos homens jamais se apaga completamente". ${ }^{11}$

Aqueles que escolhem ficar, talvez assim realizando a Escolha que dá título ao trabalho, são tomados por um suspense: acontecerá algo? Uma pessoa me relatou ter sentido um intenso ímpeto de fechar os olhos, apesar de perceber a inutilidade de tal medida. Tratava-se, talvez, de uma medida de proteção contra uma estranha potência da escuridão: fazer surgir coisas brutas, fora da cena do Eu.

Algo pode realmente acontecer, alguma presença sutil pode se mostrar na escuridão. Laura Lima recusa-se a esclarecer este ponto, mantendo um silêncio que sem dúvida é parte desta obra. Alguns espectadores (ou melhor, participadores) dizem que nada aconteceu, outros relatam a percepção da presença de alguém se movendo quase sem ruído, ou a sensação de ser tocado de maneira quase imperceptível.

No escuro, o espaço mostra sua radical imprevisibilidade, seu risco, e talvez chegue a se apresentar como a "casa" da qual o eu não é mais senhor. A casa torta e mal-delimitada, na Cultura, é o domínio sempre incerto da arte. Nela o sujeito ganha espaço, se espaça por todos os lados, disseminado e impossível de localizar, já que, como diz Freud em sua única menção a esse termo, "o espaço pode ser a projeção da extensão do aparelho psíquico [...] a psique é estendida; nada sabe a respeito". ${ }^{12}$

É nessa medida que Freud ressalta no Estranho "perturbações do eu" que se referem "à regressão a épocas nas quais o eu ainda não estava rigorosamente delimitado em relação ao mundo exterior e ao outro". ${ }^{13} \mathrm{O}$ sujeito talvez não seja mais do que o espaço.

\section{O limite do olhar}

A instalação Miragens foi realizada por Regina de Paula também na Casa França-Brasil, em 2012, no exíguo espaço que originalmente era um cofre. A artista delimitou parte da 
área deste recinto com uma parede de acrílico que ia do chão até a altura de seus olhos. Ela preencheu então de areia o espaço entre a parede de acrílico e as paredes de alvenaria do cômodo.

Diante disso, oferece-se a meu olhar muito mais do que poderia caber naquela pequena área. Como em uma súbita transformação do espaço, tenho diante de mim uma vastidão incomensurável, como se, em uma miniaturização do mundo (e de meu corpo), estivesse frente a um deserto. Renuncio a trazer aqui fotografias, pois as imagens seriam incapazes de mostrar a vivência espacial de que se trata. A artista realizou, neste trabalho, a façanha de construir um horizonte.

Um horizonte não se desenha tão facilmente quanto pode parecer, ao se fixar a linha do contorno dos prédios ou dos morros no céu, por exemplo. O perfil do que se vê, uma vez fixado em desenho, deixa de ser horizonte para se tornar paisagem. Horizonte se define como o limite do olhar. Ele está, portanto, sempre em movimento, delineando-se exclusivamente em relação à posição ocupada pelo olhador no espaço. Mas isso não quer dizer que seja possível medir a distância entre seus olhos e o horizonte. Trata-se de um espaço sempre móvel, que o olhador jamais poderá atingir: ele está sempre além.

Ao construir um horizonte, Regina de Paula derrubou as paredes tão imponentes da casa França Brasil e, sem nenhuma imagem, nos ofereceu todas as miragens, todas as dunas, todos os castelos de areia do mundo.

Essa operação topológica transformou o espaço arquitetônico, sólida e rigidamente organizado pelas leis da geometria, naquilo que Deleuze e Guattari denominam "espaço liso": aquele que resiste ao esquadrinhamento, à medição, à lógica cartográfica que nos oferece pontos de referência nos quais o eu pode se alojar. Em oposição ao espaço "estriado", ordenado como sequências de pontos entre os quais se traçam retas e se medem distâncias, o espaço liso é aquele dos vetores, das travessias que só a fortiori estabelecem seus pontos de passagem. Espaço amorfo, feito mais de volume do que de desenho, como o mar e o deserto. Espaço sem limites, aberto à mobilidade, a travessias infinitas, em todas as direções. Espaço marcado por pequenas diferenças, o que o ocupa são "as intensidades, os ventos e ruídos, as forças e as qualidades táteis e sonoras, como no deserto, na estepe ou no gelo". ${ }^{14}$ Espaço incerto - de areia movediça, talvez, ameaçando nos engolir. Espaço que, como o Homem de Areia do famoso conto de E. T. A. Hoffmann trabalhado por Freud, ameaça nos cegar e desorientar, ao jogar-nos areia nos olhos. Espaço que não se delimita visualmente e ao qual só podemos ter acesso ao fechar ao menos um olho - assim como Freud, segundo o célebre sonho que o instava a fechar um ou os dois olhos, teria que ver menos para poder entrar no espaço onírico e ali se movimentar, na interpretação, de modo nômade e múltiplo. ${ }^{15}$ 
Em contraste com o Eu, o sujeito não tem lugar - ele é um horizonte. Wo Es war, soll ich werden, como dizia Freud: onde estava isso, eu devo advir. ${ }^{16}$ Este "eu" não será mais, então, aquele que antes estava em seu lugar, mas estará sujeito, lá onde já estava isso, na Cultura. $O$ sujeito sempre estará nesse horizonte.

Não basta, contudo, fazer do lugar do sujeito uma mobilidade, uma multiplicidade de lugares em sequência ou errância, um espaço-tempo. A areia do deserto não só se desloca, levada pelo vento, e assim reconfigura incessantemente o território, mas também se fende, resiste a nossos passos e se transforma sob o peso deles. Ela cede e pode gerar deslizamentos e fendas.

Regina conta que durante a montagem de Miragens, enquanto se enchia com cerca de uma tonelada de areia o espaço do cofre, surgiam bruscas fendas. E havia um buraco, alguma brecha oculta pela qual a areia fugia, misteriosamente, impedindo que se chegasse ao nível previsto.

Robert Smithson, artista americano viculado à chamada Land Art, afirma que

A mente e a terra estão num constante estado de erosão. Rios mentais desgastam margens abstratas, ondas cerebrais escavam rochedos de pensamento, ideias se decompõem em pedras de desconhecimento e cristalizações conceituais se fragmentam em depósitos de razão arenosa. ${ }^{17}$

A mente está na terra. Intervenções sobre a natureza, que poderíamos imaginar se situar a muitas léguas da questão do sujeito, revelam-se reflexão sobre o sujeito. E propõem que se pense o sujeito arenosamente, de maneira deslizante, fendida e disseminada.

A arte indica e às vezes produz, mais do que objetos, produtos autônomos, certos acontecimentos - fendas, deslizamentos. Ela é, nela mesma, reflexão sobre o mundo e o sujeito, mas não compõe um campo bem delimitado e seguro no qual basta recolher um saber sobre o sujeito. Assim como afirma Lacan tratando mais especificamente da literatura, quando colocamos lado a lado psicanálise e arte, devemos considerar que o enigma não está do lado da última, mas sim na própria psicanálise. ${ }^{18}$ Não se trata, portanto, de buscar na arte ecos do que já afirma a teoria psicanalítica, mas sim de tentar compreender e fazer avançar a própria teoria graças à arte. Pois a arte nomeia, de forma imprevisível e sem garantias, o surgimento do sujeito na Cultura, fora dele mesmo. O aparecimento do mais íntimo fora, êxtimo.

Por isso a arte precede o saber psicanalítico. Isso não quer dizer, porém, que o artista detenha um conhecimento sobre o homem capaz de ser tomado como uma teoria. Ele opera dispositivos, arranjos simbólicos que visam efeitos de sujeito, e podem ensinar, tomados um a um, em sua singularidade, sobre os modos como o Simbólico pode revirar 
o Imaginário para fazer surgir reverberações do Real. No contrapé da colonização do Real por arranjos simbólico-imaginários, tais modos reconfigurariam o simbólico e o imaginário ao pôr o Real em primeiro plano. A própria linguagem pode eventualmente se transformar então, como visa ainda Smithson, "em montanhas de escombros simbólicos". ${ }^{19}$

A Cultura é o domínio comum do que se dá entre pessoas, em compartilhamento. Ela só é lugar de extimidade, porém, quando se presta a produzir fendas e abrir espaço na massa compacta de imagens fixadoras do eu que organiza tanto o domínio público quanto o privado. Em vez de reforçar o compartilhamento, a arte parece-me implicar uma certa transmissão: a passagem de uma centelha de subversão do sujeito. Ela é o terreno designado culturalmente (apesar de bastante mal delimitado) no qual isso pode ocorrer, fora das quatro paredes do consultório psicanalítico. O diálogo com a arte não confirma ou complementa, assim, aquilo que o psicanalista só aprenderia na individualidade de cada tratamento, em seu consultório. Como o sujeito do inconsciente não coincide com a interioridade do indivíduo na qual acredita a psicologia, seu lugar de direito não é aquele da fala íntima, mas aquele do acontecimento êxtimo. Trabalhos de arte podem, portanto, informar o analista de modo a fazê-lo ouvir outra coisa, comum, na singularidade da associação livre de cada analisando: o êxtimo.

* Tania Rivera é professora associada do Departamento de Artes da UFF.

${ }^{1}$ LACAN, J. Le Séminaire, livre vii: L'Éthique de la Psychanalyse. Paris: Seuil, 1986.

2 MALLARMÉ, S. "Richard Wagner: rêverie d'un poète français". In: Écrits sur l'art. Paris: Flammarion, 1998/1885, pp. 364-368, aqui p. 364. É minha a tradução deste e de todos os demais trechos em língua estrangeira aqui citados.

3 TZARA, T. "Manifeste Dada 1918". In: Dada est Tatou. Tout est Dada. Paris: Flammarion, 1996/1918, pp. 203-213, aqui p. 208.

${ }^{4}$ FREUD, S. "Lembranças encobridoras". In: Edição Standard das Obras Psicológicas Completas. Vol. III. Rio de Janeiro: Imago, 1987/1889, pp. 269-287.

${ }^{5}$ Ver a este respeito RIVERA, T. Cinema, imagem e psicanálise. Rio de Janeiro: Jorge Zahar, 2005.

${ }^{6}$ LACAN, J. "O estádio do espelho como formador da função do eu". In: Escritos. Rio de Janeiro: Jorge Zahar, 1998/1966, pp. 96-103, aqui pp. 96-97.

${ }^{7}$ LISSITSKY, E. "Proun Space. The Great Berlin Art Exhibition of 1923". In: Russia: An Architecture for World Revolution. Cambridge, Massachusetts: MIT Press, 1984/1923, pp. 138-141, aqui p.138.

${ }^{8}$ MERLEAU-PONTY, M. L'Oeil et L'Esprit. Paris: Gallimard, 1992/1964, p. 50.

9 JENTSCH, E. "Zur Psychologie des Unheimlichen". In: Psychiatrisch-Neurologische 
Wochenschrift, n. 22 (25 de agosto de 1906), pp. 195-205, aqui p.195.

${ }^{10}$ FREUD, S. "Das Unheimliche”. In: Gesammelte Werke. Vol. XII. Londres: Imago, 1955/1919, pp. 229-268, aqui p. 231.

${ }^{11}$ FREUD, S. "Das Unheimliche". Op. cit., p. 268.

12 FREUD, S. "Resultados, ideias, problemas". Edição Standard das Obras Psicológicas Completas. Vol. XXIII. Rio de Janeiro: Imago, 1987/1938, pp. 335-336, aqui p. 336.

${ }^{13}$ FREUD, S. "Das Unheimliche”. Op. cit., p. 249.

${ }^{14}$ DELEUZE, G.; GUATTARI, F. Mil platôs. Capitalismo e esquizofrenia. Volume V. São Paulo: Ed. 34, 1997/1980, p. 185.

${ }^{15}$ FREUD, S. A interpretação dos sonhos. Porto Alegre: L\&PM, 2012/1900.

${ }^{16}$ FREUD, S. "Neue Folge der Vorlesungen zur Einführung in die Psychoanalyse". In: Gesammelte Werke. Vol. XII. Londres: Imago, 1961/1933, p. 86.

17 SMITHSON, R. "Uma sedimentação da mente: projetos de terra". In: FERREIRA, G.; COTRIM, C. (orgs.) Escritos de artistas anos 60/70. Rio de Janeiro: Jorge Zahar, 2006/1968, pp. 182-197, aqui p. 182.

${ }^{18}$ LACAN, J. “Lituraterre”. In: Autres Écrits. Paris: Seuil, 2001/1971, pp. 11-20.

${ }^{19}$ SMITHSON, R. Op. cit., p. 194. 